\title{
Family Physician-Case Manager Collaboration and Needs of Patients With Dementia and Their Caregivers: A Systematic Mixed Studies Review
}

\author{
Vladimir Kbanassov, MD, MSc \\ Isabelle Vedel, $M D, P b D$
}

Department of Family Medicine, McGill University, Montreal, Canada
Conflicts of interest: authors report none.

\section{CORRESPONDING AUTHOR}

Vladimir Khanassov, MD, MSc Family Medicine Center, St Mary's Hospital McGill University

3830 avenue Lacombe, Montréal, (Québec) H2T 1 M5 Canada

vladimir.khanassov@mail.mcgill.ca

\begin{abstract}
PURPOSE Dementia case management (CM) in primary care is a complex intervention aimed at identifying the various needs of patients with dementia and their caregivers, as well as the organization and coordination of care. A key element of CM is the collaboration of family physicians with case managers. We conducted a systematic mixed-studies review to identify the needs of the patientcaregiver dyad and the effects of CM.
\end{abstract}

METHODS We searched MEDLINE, PsycINFO, and EMBASE up to October 2014, regardless of the study design. Our main outcomes were needs of patients and their caregivers and the effects of CM on these needs. We used narrative syntheses to develop a taxonomy of needs and to describe the effects of CM on those needs. We used meta-analysis to calculate the prevalence of needs and the standardized mean differences to evaluate the effects of $C M$ on the needs identified.

RESULTS Fifty-four studies were included. We identified needs of the patientcaregiver dyad and needs of the patient and caregiver individually. CM addressed the majority of the identified needs. Still, some very common needs (eg, early diagnosis) are overlooked while other needs (eg, education on the disease) are well addressed. Fully establishing the value of CM is difficult given the small number of studies of CM in primary care.

CONCLUSIONS There is good evidence that case managers, in collaboration with family physicians, have a pivotal role in addressing the needs of the patientcaregiver dyad.

Ann Fam Med 2016;14:166-177. doi: 10.1370/afm.1898.

\section{INTRODUCTION}

The proportion of people with dementia is growing dramatically. According to the US Alzheimer's Association, by 2030, 50\% of Americans aged 65 years and older will be diagnosed with dementia. ${ }^{1}$ In Canada in 2011, 747,000 Canadians lived with cognitive impairment. ${ }^{2}$ Today, the combined costs are $\$ 33$ billion per year, ${ }^{1}$ and they are projected to increase to $\$ 872$ billion by $2038 .^{3,4}$ Worldwide, dementia is the main contributor to disability-adjusted life years (11.2\%), representing a greater burden than cerebral vascular accident $(9.5 \%)$, heart disease $(5.0 \%)$, or cancer $(2.4 \%){ }^{5}$

People with dementia need help with challenging changes in behavior, memory, physical disability, and mood. ${ }^{6}$ The main source of help is family caregivers, who often suffer from the burdens of caregiving and from depression and health problems. ${ }^{7}$ It has been shown that early intervention makes the greatest difference in management of symptoms. ${ }^{1}$ The World Health Organization states that it would be challenging to intervene without effective involvement of primary care. ${ }^{8}$ Dementia case management (CM) interventions are becoming a central component of primary health care organizations in North America and Europe. ${ }^{9-12}$ According to the 
Case Management Society of America, case management is "a collaborative process of assessment, planning, facilitation, care coordination, evaluation, and advocacy for options and services to meet an individual's and family's comprehensive health needs through communication and available resources...."13 Case managers are health care professionals who provide follow-up, coordinate individual care, and liaise with other health care services. They work in collaboration with family physicians, specialists, or both. ${ }^{14-22}$

Over the last few years, several systematic reviews have found that the evidence of CM's effects on service use and clinical outcomes is weak. ${ }^{23-28}$ None of them specifically focused on the needs of patients and caregivers, however. ${ }^{23-28}$ Patients with dementia and their caregivers who already receive professional care still report unmet needs. ${ }^{29}$ Moreover, they feel that their own opinion is not taken into account. ${ }^{30}$ In line with the patient-centered care paradigm, ${ }^{31,32}$ it is important to identify the needs felt by the patient and the caregiver ${ }^{33-35}$ and to determine the extent to which $\mathrm{CM}$ interventions respond to their needs. ${ }^{36}$

We conducted a systematic review to answer the following research question: Does the collaboration of family physicians with case managers respond to the needs of patients with dementia and their caregivers living in the community?

\section{METHODS}

We conducted a systematic mixed-studies review by including studies with diverse designs (quantitative, qualitative, and mixed methods). ${ }^{37}$ This type of review has been deemed appropriate for the study of complex interventions..$^{38}$ It overcomes the issue of a partial picture that results from relying on a single type of research in isolation, assists in the critical analysis of interventions from the viewpoint of participants targeted ${ }^{39}$ and enables a single review to answer a number of questions (eg, identifying needs and evaluating how well they have been met).$^{40}$ It produces research more useful for decision makers and maximizes the use of review results (maximizes the conversion of knowledge to action) by enhancing their utility and impact. ${ }^{39}$

\section{Inclusion Criteria}

To be included in our review, studies had to meet the following criteria:

- They had to deal with community-dwelling patients of any age with any type of dementia and/or their informal caregivers.

- They had to concern collaboration between a family physician and a case manager that comprises a comprehensive needs and health assessment, planning of services and their coordination, monitoring, and regular proactive follow-up..$^{3,41}$

- They had to focus on primary medical care, defined as a range of community settings where family physicians intervene (patients' homes and offices). ${ }^{42}$

- They could be of any type or design.

- Their outcomes could be the effects of CM on any type of need expressed by patients, expressed by caregivers, or measured.

\section{Search Strategy and Study Selection}

In accordance with PRISMA statement standards ${ }_{1}{ }^{43}$ a literature search was conducted by a specialized librarian, publications in English, French, or Russian listed in MEDLINE, PsycINFO, or EMBASE, published before October 2014, were searched (Supplemental Appendix 1, available at http://annfammed.org/content/14/2/166/ suppl/DC1). Given the objectives of our review, 2 search strategies were applied in parallel: 1) studies of the needs of community-dwelling patients with dementia and their caregivers, and 2) studies of CM (Supplemental Figure, available at http://annfammed.org/ content/14/2/166/suppl/DC1). Based on the eligibility criteria, relevant titles, abstracts, and full-text articles were selected independently by 1 author (V.K.) and a research assistant (Martin Beauchamp).

\section{Quality Assessment}

The quality of the studies was assessed independently by 1 author (V.K.) and one outside reviewer (Quan Nha Hong, MSc) using the validated Mixed Methods Appraisal Tool designed for the critical appraisal of studies with diverse designs. ${ }^{44-46}$ Studies were scored on their internal and external validity (eg, representativeness of the sample, randomization). Studies were included without regard to their quality. We performed a sensitivity analysis (with a potential score of 0 or 1 ) to assess the impact of lower-quality studies on the results.

\section{Data Extraction and Synthesis}

Two reviewers (V.K. and Beauchamp) independently extracted and coded data ${ }_{i}$ discrepancies were resolved through consensus. We used a 3-step approach to synthesize the findings:

1. We defined a need as a perceived state of deprivation communicated by patients or their caregivers. ${ }^{6}$ The prevalence was extracted if it was reported. Needs expressed in other domains measured by instruments were also searched (eg, domains of quality of life). ${ }^{6}$ We used a narrative synthesis approach to develop a taxonomy of the needs and meta-analysis to evaluate their prevalence.

2. A narrative synthesis approach was applied to describe the key components of CM. 
3. A narrative synthesis was used to describe CM effects on the needs (mapping of CM components to the needs identified in Step 1) and a meta-analysis to estimate their effects.

Narrative synthesis was the main analytical approach we used, while meta-analyses were performed to explore the observed effects (Table 1).

\section{RESULTS}

Fifty-four studies were included in the review: 46 on the needs of patients and their caregivers ${ }^{52-98}$ and 8 on CM (Supplemental Figure, available at http://annfammed.org/content/14/2/166/suppl/DC1). The characteristics of the included studies are presented in Table 2, and Supplemental Appendixes 2 and 3, available at http://annfammed.org/content/14/2/166/suppl/DC1.

\section{Identification of Needs}

Three main categories of need were identified and are presented in Table 3: needs of the patient-caregiver dyad, needs of the patient, and needs of the caregiver. Many needs are common to patients and caregivers. The needs reported by the largest number of studies are needs of the dyad: for education or counseling on the disease (32 studies) and early diagnosis (13 studies).

Meta-analyses showed that 58\% (95\% CI, 43\%$72 \%$ ) of caregivers were in favor of early dementia diagnosis, $50 \%(95 \% \mathrm{CI}, 35 \%-65 \%)$ were in need of education on the disease, and $23 \%$ (95\% CI, 17\%-31\%) needed in-home support (Table 4). Needs for meaningful activities that patients could participate in and assistance with daily activities were reported by $36 \%(95 \%$ CI, $5 \%-85 \%)$ and $22 \%(95 \% \mathrm{CI}, 5 \%-59 \%)$ of patients with dementia respectively.

\section{Description of Care Management}

A key component of CM apparent in the studies we examined was close collaboration between case managers and family physicians (Supplemental Appendix 3, available at http://annfammed.org/content/14/2/166/ suppl/DC1). The case managers involved were nurses specialized in care of the elderly. ${ }^{14-18,20}$ They were responsible for the coordination of treatment plans and for providing services. Through phone calls, web-based interactions, and case discussions, case managers communicated regularly with family physicians to inform them about patient and caregiver health conditions and needs. ${ }^{14-22}$ The role of family physicians was to develop care plans, provide medical treatment, and to modify care plans based on updates from case managers.

We mapped the components of CM to the needs identified from the perspectives of the patients and their caregivers (Table 5). To meet the needs of the patient-caregiver dyad, case managers performed the prediagnostic work-up to assist family physicians with

\section{Table 1. Description of Synthesis}

\begin{tabular}{|c|c|}
\hline $\begin{array}{l}\text { Narrative synthesis } \\
\text { (main approach) }\end{array}$ & $\begin{array}{l}\text { Through a narrative synthesis, we developed an integrated interpretation of various primary studies from which con- } \\
\text { clusions may be drawn. }{ }^{47} \text { This synthesis provides qualitative rather than quantitative data. }{ }^{48} \text { We followed a narrative } \\
\text { approach that includes textual description of studies on needs of the patient and caregiver, extraction of the needs } \\
\text { and their grouping into categories based on their common features (eg, education on disease), and then transforming } \\
\text { data into common rubrics (taxonomy development). }{ }^{37} \text { We divided the identified needs into } 3 \text { categories: needs of the } \\
\text { patient, needs of the caregiver, and needs common to both (needs of the dyad). }\end{array}$ \\
\hline Meta-analysis & $\begin{array}{l}\text { We performed a meta-analysis on quantitative studies only to determine the prevalence of the needs identified. Starting } \\
\text { with the prevalence proportions extracted from each study, we used R } 3.1 .2 \text { (The R Foundation) to calculate the pooled } \\
\text { prevalence proportion and } 95 \% \text { confidence interval for each need. }{ }^{49} \text { We employed random-effects models, since the } \\
\text { studies were statistically and methodologically heterogeneous. The } I^{2} \text { statistic was used to measure heterogeneity. Con- } \\
\text { sidering the context (needs are generally evaluated in the observational studies) the meta-analysis included studies of } \\
\text { different designs (eg, nonrandomized studies and surveys). }{ }^{50}\end{array}$ \\
\hline \multicolumn{2}{|c|}{ Step 2. Description of case management } \\
\hline $\begin{array}{l}\text { Narrative } \\
\text { description }\end{array}$ & $\begin{array}{l}\text { We described the main features of CM according to the definition of the Case Management Society of America, }{ }^{13} \text { then } \\
\text { mapped the various components of CM to the needs identified in Step } 1 \text { that they targeted. }\end{array}$ \\
\hline \multicolumn{2}{|c|}{ Step 3. Evaluation of case management effects by narrative synthesis and meta-analysis } \\
\hline Meta-analysis & $\begin{array}{l}\text { We then conducted a meta-analysis to explore the potential effects of CM on the identified needs where data were avail- } \\
\text { able. At this point, we included only randomized controlled trials at } 12 \text { months follow-up. Meta-analyses were con- } \\
\text { ducted on the effects of CM on needs (eg, the need for confidence in caregiving) and on surrogate markers of needs } \\
\text { (eg, behavior management as a surrogate for behavior disturbance of the patient and emotional support as a surrogate } \\
\text { for depression and burden of the caregiver). To evaluate the intervention effect, we calculated the standardized mean } \\
\text { differences between groups along with } 95 \% \text { confidence intervals, since different scales were used to measure the same } \\
\text { outcome. To obtain missing data, we contacted the authors. Fixed-effects models were used because of the small } \\
\text { sample size ( } 2 \text { in each outcome evaluation). }{ }^{50,51}\end{array}$ \\
\hline
\end{tabular}


Table 2. Summary Characteristics of Included Studies

\begin{tabular}{|c|c|c|}
\hline \multirow[b]{2}{*}{ Characteristics } & \multicolumn{2}{|l|}{ Description } \\
\hline & Studies of Needs & Studies of CM \\
\hline \multicolumn{3}{|l|}{ Continent/country: } \\
\hline \multirow[t]{2}{*}{ Americas, (16 studies) } & USA $A^{61,62,66,73,74,76,81,85,91,93,95,97}$ & USA $A^{14-16}$ \\
\hline & Canada ${ }^{84}$ & \\
\hline \multirow[t]{5}{*}{ Europe (21 studies) } & UK $^{20,52,53,64,69,72,77,78,83,84,99}$ & $\mathrm{UK}^{20}$ \\
\hline & The Netherlands ${ }^{17,19,54,75,79,86}$ & The Netherlands $s^{17,19}$ \\
\hline & Sweden $21,22,70$ & Sweden 21,22 \\
\hline & Norway ${ }^{97}$ & Belgium ${ }^{18}$ \\
\hline & Italy ${ }^{85}$ & \\
\hline \multirow[t]{2}{*}{ Oceania (5 studies) } & Australia $65,67,88,98$ & $\ldots$ \\
\hline & New Zealand ${ }^{71}$ & \\
\hline \multirow[t]{6}{*}{ Asia (7 studies) } & China $^{68}$ & $\ldots$ \\
\hline & Hong Kong 90,96 & \\
\hline & Singapore ${ }^{59}$ & \\
\hline & $J \operatorname{lapan}^{82}$ & \\
\hline & Pakistan ${ }^{57}$ & \\
\hline & Turkey $^{58}$ & \\
\hline Africa (1 study) & Tanzania 55 & $\ldots$ \\
\hline \multirow{3}{*}{$\begin{array}{l}\text { Multiple countries } \\
\text { (3 studies) }\end{array}$} & UK - Poland ${ }^{87}$ & $\ldots$ \\
\hline & USA - Canada ${ }^{56}$ & \\
\hline & $\begin{array}{l}\text { Germany - UK - France - Poland - } \\
\text { Spain - Luxembourg94 }\end{array}$ & \\
\hline \multirow[t]{4}{*}{ Type of studies } & $12 \mathrm{NRS}^{74-86}$ & $5 \mathrm{RCTs}^{14,16-19}$ \\
\hline & 11 quantitative descriptive studies ${ }^{87-97}$ & 2 NRS $^{15,20}$ \\
\hline & 22 qualitative studies ${ }^{52-73}$ & 1 quantitative descrip- \\
\hline & 1 mixed methods study ${ }^{98}$ & tive study ${ }^{21,22}$ \\
\hline \multicolumn{3}{|l|}{$\begin{array}{l}\text { Demographic characteris- } \\
\text { tics of participants }\end{array}$} \\
\hline $\begin{array}{l}\text { Age of patients (care- } \\
\text { givers), mean, } y\end{array}$ & $77(58)$ & $79(61)$ \\
\hline \multicolumn{3}{|l|}{ Type of dementia } \\
\hline Alzheimer's disease, \% & 59.8 & 57.6 \\
\hline Vascular dementia, \% & 14.0 & 17.0 \\
\hline Early onset of dementia & 3 studies $^{53,54,88}$ & \\
\hline $\begin{array}{l}\text { Frontotemporal } \\
\text { dementia }\end{array}$ & 2 studies $^{56,89}$ & \\
\hline Severity of dementia & Mild to moderate & Mild to moderate \\
\hline
\end{tabular}

To meet the needs of caregivers, case managers provided support sessions and non-pharmacologic interventions for stress management ${ }^{14,15,17}$ and coping skills. ${ }^{14}$ They also developed care plans ${ }^{14-18,20-22}$ and coordinated home care services ${ }^{16-18}$ and social services. ${ }^{16,17,21,22}$

\section{Evaluation of the Effects of Care Management}

CM was able to address almost all identified needs (Table 5). The number of diagnoses made by family physicians working with case managers increased while the rate of diagnosis by specialists without case managers remained stable. ${ }^{21,22} \mathrm{CM}$ led to better education on the disease $^{15,16,20}$ and provision of sufficient information on dementia-specific community resources. ${ }^{15,20}$ No effect on the understanding of medical treatment and knowledge of dementia was shown in 1 study, however. ${ }^{16}$ $\mathrm{CM}$ proved to establish good coordination of health care services, continuity, and quality of care, ${ }^{14-17}$ except in 1 study. ${ }^{18}$

$\mathrm{CM}$ also better addressed the needs of patients. More patients received non-pharmacologic behavioral protocols. ${ }^{16}$ Acetylcholinesterase inhibitors were more frequently prescribed by family physicians working with case managers, while neuroleptics prescription decreased. ${ }^{21,22}$ More patients were enrolled in the Safe Return program. ${ }^{16}$

$\mathrm{CM}$ also showed effects on the needs of caregivers. Caregivers' confidence with care increased. ${ }^{16}$

diagnosis. ${ }^{21,22}$ They provided education on the disease, prognosis, treatment, ${ }_{1}^{16,17,19,21,22}$ and problematic home situations. ${ }^{18}$ They counseled on available resources/ services, ${ }^{16,20}$ legal and financial issues, and advance directives. ${ }^{14-16}$ Finally, case managers coordinated medical and community services via electronic, written, and case conference discussion. ${ }^{14-17,19,20}$

To meet the needs of patients, case managers applied, in collaboration with family physicians, nonpharmacologic and pharmacologic protocols for management of daily activities, ${ }_{1}^{14-16}$ behavior distress, ${ }_{1}^{14-16,21,22}$ cognition, ${ }^{14-16}$ mood $_{1}^{14-16}$ and home safety. ${ }^{16,18,19}$
Their decision-making capacity improved, ${ }^{15,16}$ as did satisfaction with social support ${ }_{1}^{16}$ and in-home help (eg, cleaning services). ${ }^{16,17}$ Moreover, caregivers were actively involved in care-plan development and regular discussion of the patient's health problems. ${ }^{16,17}$

The effects on the needs for early diagnosis, financial and legal aspects of the disease, and meaningful activities were not studied. CM was not found to have any effect on patients' daily activities, cognition and depression.

A meta-analysis of the effects of CM (Figure 1 and Supplemental Appendix 4, available at http:// 
annfammed.org/content/14/2/166/suppl/DC1) showed a significant decrease in behavioral disturbance of patients as a result of psychosocial interventions along with acetylcholinesterase inhibitors (standardized mean difference $[\mathrm{SMD}]-0.27,95 \% \mathrm{CI},-0.53$ to -0.01 , $P=.04)^{14,17}$ and a significant increase of confidence in caregiving (SMD 0.19, 95\% CI, 0.01-0.37, P=.04) due to the education in coping skills. ${ }^{16,17}$ The effect on depression of caregivers was uncertain (SMD -0.23, $95 \% \mathrm{CI},-0.46$ to $0.01, P=.06),{ }_{1}^{14,17,18}$ and there was no effect on caregivers' burden (SMD 0.17, 95\% CI, -0.18 to $0.52, P=.34$ ).

\section{Quality of Evidence}

Almost all studies (43 studies) of the needs of the dyad and all 8 studies of CM proved to be of high quality. The majority of RCTs clearly described the randomization, blinding, and drop-out rate. Most non-randomized and quantitative descriptive studies (surveys) reported adequate sampling strategies and measurements.

\section{Table 3. Needs of Community Dwelling Patients With Dementia and Their Caregivers}

\begin{tabular}{|c|c|c|}
\hline Categories of Need & Description & $\begin{array}{l}\text { No. of } \\
\text { Studies }\end{array}$ \\
\hline \multicolumn{3}{|l|}{ Needs of the patient/caregiver dyad } \\
\hline Early diagnosis $52-54,56,64-66,73,80,85,87-89$ & $\begin{array}{l}\text { Need for early diagnosis (to understand the behavioral problems and gain timely } \\
\text { access to resources). }\end{array}$ & 13 \\
\hline $\begin{array}{l}\text { Education/ } \\
\text { counseling } 54-52,59-68,72-75,79,80,82,85-89,92-97\end{array}$ & $\begin{array}{l}\text { Need for specific information on medical and interpersonal aspects of the disease, } \\
\text { meaningful counseling on dealing with behavioral problems, guidelines on demen- } \\
\text { tia before and after diagnosis. }\end{array}$ & 32 \\
\hline $\begin{array}{l}\text { Information about relevant } \\
\text { services }{ }^{65,74,75,82,83,85,89,92,94,96,98}\end{array}$ & $\begin{array}{l}\text { Need for an overview of available formal care services such as community psychiatric } \\
\text { services, domestic help, caregivers' support groups, and insurance. }\end{array}$ & 11 \\
\hline Legal assistance ${ }^{66,85,93,97}$ & $\begin{array}{l}\text { Need for assistance with legal documents and advice on guardianship, power of } \\
\text { attorney, etc. }\end{array}$ & 4 \\
\hline $\begin{array}{l}\text { Financial support/ } \\
\text { planning } 53,55,57,59,66,88,89,92,93,96,97\end{array}$ & $\begin{array}{l}\text { Need for assistance with access to financial programs that can help if the caregiver } \\
\text { quits a job to take care of the patient and help deal with household and medica- } \\
\text { tion expenses. }\end{array}$ & 11 \\
\hline $\begin{array}{l}\text { Care coordination/continu- } \\
\text { ity of care/well-defined care } \\
\text { pathway } 52-54,64,65,67,68,73,86,98\end{array}$ & $\begin{array}{l}\text { Need for continuity between the various health care services involved, access to ser- } \\
\text { vices corresponding to the severity of the disease, support throughout the course } \\
\text { of the disease from the same health care professionals, and coordination of medi- } \\
\text { cal and community services to optimize services and prevent overlap. }\end{array}$ & 10 \\
\hline $\begin{array}{l}\text { Access to family physicians trained in } \\
\text { geriatrics } 52-54,66,86,88,92\end{array}$ & $\begin{array}{l}\text { Need for access to a family physician who has adequate knowledge of the disease, is } \\
\text { sensitive to the concerns of patient and caregiver, can provide guidance on demen- } \\
\text { tia, and can follow patients with dementia and their caregivers. }\end{array}$ & 7 \\
\hline $\begin{array}{l}\text { Access to other health care profession- } \\
\text { als trained in geriatrics } 65,70,73,81,86-88\end{array}$ & $\begin{array}{l}\text { Need for access to health care professionals who know the disease, respond compe- } \\
\text { tently at disclosure of the diagnosis, and communicate test results clearly. }\end{array}$ & 7 \\
\hline \multicolumn{3}{|l|}{ Needs of the patient } \\
\hline Meaningful activities $60,74,77-79,84,85,90,95$ & Need to take part in activities, join in with others, do things, and have company. & 9 \\
\hline $\begin{array}{l}\text { Assistance with ADL/IADL } 57,68,74,76,79,84 \\
85,87,88,91,97\end{array}$ & $\begin{array}{l}\text { Need for help with ADL (commonly for bathing/dental care, dressing, and walk- } \\
\text { ing) and with IADL (commonly for housekeeping, meal preparation, and } \\
\text { transportation). }\end{array}$ & 11 \\
\hline Behavior management $63,75,84,87,88,90,91,95,97$ & $\begin{array}{l}\text { Need for pharmacologic and nonpharmacologic approaches to managing the behav- } \\
\text { ioral spectrum of the disease, especially agitation and restlessness, verbal aggres- } \\
\text { sion, and anxiety. }\end{array}$ & 9 \\
\hline $\begin{array}{l}\text { Management of mood swings/ } \\
\text { depression }\end{array}$ & Need for pharmacologic and nonpharmacologic approaches to managing depression. & 7 \\
\hline Safety $69,74,77,78,84,85,91,97$ & $\begin{array}{l}\text { Need for help in managing fall and wander risk, ensuring home safety, and minimiz- } \\
\text { ing the risk of accidental self-harm. }\end{array}$ & 8 \\
\hline \multicolumn{3}{|l|}{ Needs of the caregiver } \\
\hline Emotional support $53,57,59,62-64,74,80,95,97$ & $\begin{array}{l}\text { Need for assistance with feelings of being alone, abandoned, helpless, exhausted, } \\
\text { and mentally burdened. }\end{array}$ & 10 \\
\hline Social support $53,56,58,59,62,67,75,81,87,88,91,97$ & $\begin{array}{l}\text { Needs to have social outlets such as time alone, social interaction with friends, } \\
\text { opportunities to shop and to go out. }\end{array}$ & 12 \\
\hline In-home support ${ }^{55,58,66,75,83,95}$ & Need for help with house chores (eg, cleaning). & 6 \\
\hline Capacity to provide care $62,63,80,87,89,90,96,97$ & $\begin{array}{l}\text { Need for training in communication skills and in strategies for handling maladaptive } \\
\text { behaviors and. }\end{array}$ & 8 \\
\hline Involvement in care planning ${ }^{65}$ & Need to be included as an equal partner in formal and informal care planning. & 1 \\
\hline
\end{tabular}

$\mathrm{ADL}=$ activities of daily living; $\mathrm{IADL}=$ instrumental activities of daily living.

Note: Needs for help with urinary incontinence, ${ }^{66,84}$ help with sight and hearing problems, ${ }^{77,78,97}$ and culturally sensitive services ${ }^{61}$ are not presented in the table, since only a few studies evaluated these needs. 
Table 4. Meta-Analysis of Needs of Patients and Their Caregivers

\begin{tabular}{|c|c|c|c|c|}
\hline Categories of Need & $\begin{array}{l}\text { No. of } \\
\text { Studies }\end{array}$ & $\begin{array}{l}\text { Pooled Proportion } \\
\qquad(95 \% \mathrm{CI})\end{array}$ & $\begin{array}{l}\text { Variation Across } \\
\text { Studies }\left(1^{2}\right), \%\end{array}$ & $\begin{array}{l}\text { Test of Heterogeneity } \\
\left(Q^{2}\right), P \text { value }\end{array}$ \\
\hline \multicolumn{5}{|l|}{ Needs of the patient-caregiver dyada } \\
\hline Early diagnosis ${ }^{80,88,89}$ & 3 & $0.58(0.43-0.72)$ & 80.0 & .007 \\
\hline Education/counseling on disease $\mathrm{e}^{79,80,82,89,92,94-96}$ & 8 & $0.50(0.35-0.65)$ & 97.3 & $<0.001$ \\
\hline \multicolumn{5}{|l|}{ Needs of the patient ${ }^{b}$} \\
\hline Meaningful activities ${ }^{74,79,85}$ & 3 & $0.36(0.05-0.85)$ & 97.8 & $<0.001$ \\
\hline Assistance with $\mathrm{ADL} / \mathrm{IADL} \mathrm{L}^{74,79,85}$ & 3 & $0.22(0.05-0.59)$ & 95.5 & $<0.001$ \\
\hline \multicolumn{5}{|l|}{ Needs of the caregiver ${ }^{\mathrm{a}}$} \\
\hline In-home support ${ }^{75,83,95}$ & 3 & $0.23(0.17-0.31)$ & 17.7 & 0.30 \\
\hline \multicolumn{5}{|c|}{$A D L=$ activities of daily living; IADL = instrumental activities of daily living } \\
\hline $\begin{array}{l}{ }^{\mathrm{a}} \text { Needs reported by caregivers. } \\
\mathrm{b} \text { Needs reported by patients. }\end{array}$ & & & & \\
\hline
\end{tabular}

Table 5. Mapping of Components of Case Management to Needs and Their Effects on the Needs

\section{Corresponding Components of Case}

Needs of the patient/caregiver dyad

Early diagnosis $\quad$ Gathering information through the basic diagnostic battery to help family physicians establish a diagnosis ${ }^{21,22}$

Education/counseling Holding interactive seminars and family meetings for on disease patients and caregivers on relevant care issues ${ }^{16,17}$ Providing information by phone to caregivers ${ }^{17,18}$ Helping the patient and family understand the disease, prognosis, and rationale of treatment ${ }^{19,21,22}$

Exploring problematic home care situations ${ }^{18}$

Information on relevant services

Help with legal issues

Financial support and planning

Advance care planning continuity of care, and a well-defined care pathway
Recommending caregiver resources-eg, Alzheimer's Association, meals on wheels, and Safe Return program (for wandering) ${ }^{16}$

Helping with various services (day care, respite care) ${ }^{20}$

Educating caregivers on legal issues ${ }^{14,15}$

Educating caregivers on dementia-related financial planning ${ }^{14-16}$

Advising on advance directives ${ }^{16}$

Interactive seminars for caregivers on evaluation of decision-making capacity ${ }^{16}$

Communicating regularly with family physicians, ${ }^{14,15,17,19}$ maintaining written consultation notes, ${ }^{14,16}$ producing secure electronic updates, ${ }^{15}$ via web-based systems, ${ }^{14,16}$ and attending case conferences ${ }^{14,20}$

Connecting patients and their caregivers to support services ${ }^{16,17,19}$

Operating in conjunction with any services patient already had 20

\section{Resultant Effects}

Dementia diagnosis increased in primary care while remaining stable in specialty care ${ }^{21,22}$

Caregivers understood medical treatment for behavior and depression: $78.4 \%$ vs $72.2 \%$ in usual care $(P=.49)^{6}$

Perception of caregiver's clarity in discussing patient's care: $16.8 \%$ vs $21.3 \%$ of usual care $(P=.01)^{16}$

$100 \%$ of caregivers were satisfied with the ability of case managers to answer questions ${ }^{15}$

Educational material was relevant to the dyad situation in $95 \%$ of cases $^{15}$

$95 \%$ of caregivers were satisfied with quality of educational material provided ${ }^{15}$

A majority of caregivers were satisfied with information allowing them to understand the nature of the disease ${ }^{20}$

Caregiver knowledge about dementia was not improved $(P=.19)^{16}$

$97 \%$ of caregivers were satisfied with the information they received on community resources ${ }^{15}$

Caregivers were more aware of dementia-specific resources ${ }^{20}$

Not evaluated

Not evaluated

With CM, advance directives were discussed or completed and documented in $69.4 \%$ of cases, vs $44.4 \%$ in usual care $(P=.001)^{16}$

Decision-making capacity improved in $34.2 \%$ of patients vs $9.7 \%$ in usual care $(P=.001)^{16}$

$90 \%$ of caregivers were satisfied with future planning ${ }^{15}$

$70 \%$ to $82.8 \%$ of caregivers rated a new way of primary care delivery as very good/excellent ${ }^{14}$

$88 \%$ of caregivers were satisfied with the care coordination provided $^{15}$

$100 \%$ of caregivers stated that intervention was efficient ${ }^{17}$ $95 \%$ of caregivers were satisfied with the ability of case managers to link them with community resources ${ }^{15}$

The quality of patient's health care improved $(P=.003)^{16}$

1 study found no difference in interdisciplinary communication between intervention and usual care group $(P=.5)^{18}$

continues 
Table 5. Mapping of Components of Case Management to Needs and Their Effects on the Needs (continued)

Categories of Need

Access to health
care profession-
als trained in
geriatrics

Access to family physician trained in geriatrics

Needs of the patient

Meaningful activities

Assistance with ADL/ IADL

Behavior management

Cognition management

Management of mood swings/ depression

Safety

Needs of the caregiver Emotional support

Social support

In-home support

Capacity to provide care

Involvement in care planning
Corresponding Components of Case

Management

\section{Resultant Effects}

Case managers are trained in geriatrics/geropsychiatry, ${ }_{14-18,20}$ communicating the diagnosis to the families, ${ }^{14}$ skills in communicating with patients and their caregivers, ${ }^{17}$ dementia home care $^{18}$

Involving a multidisciplinary team in patient care (eg. geriatrician, geriatric psychiatrist, and psychologist) ${ }^{14}$ Helping with access to health care professionals ${ }^{19}$

Referring to specialists if needed $17,21,22$

No prior formal training of family physicians in geriatrics

Providing patient exercise guidelines and resources (eg, group chair-based exercises) $)^{14,15}$

Advising on implementation of predictable routine of daily activities ${ }^{16}$

Providing nonpharmacologic protocols that include mobility management, personal care concerns ${ }^{14,15}$

Arranging interactive seminars for caregivers on evaluation of acute behavior changes ${ }^{16}$

Providing specific protocols and nonpharmacologic interventions for repetitive behavior, agitation, aggression, delusions or hallucinations $s^{14-16}$

Providing drug therapy with anticholinesterase inhibitors and memantine ${ }^{14,16,21,22}$

Assessing patients' memory regularly ${ }^{14-16}$

Educating on communication ${ }^{14}$ and applying nonpharmacologic protocols that include communication techniques ${ }^{15}$

Providing a specific protocol of nonpharmacologic interventions on depression, with drug therapy as a backup ${ }^{14,15}$

Arranging interactive seminars for caregivers on managing depression in patients ${ }^{16}$

Making recommendations on home safety and the Safe Return program (for wandering) ${ }^{16}$

Providing personal alarms ${ }^{18}$

Assessing the patient's home situation ${ }^{19}$

Guiding the caregiver in organizing home $\operatorname{care}^{18}$

Providing support sessions focused on caregiver stress $^{14,17}$;

Recommending nonpharmacologic protocols that includes stress management ${ }^{15}$

Recommending a caregiver support group ${ }^{16}$;

Organizing family meetings aimed at improving social support and relieving the primary caregiver ${ }^{17,21,22}$

Helping with home care, ${ }_{1}^{17,18}$ meals on wheels, ${ }^{16}$ and dinner services ${ }^{17}$

Educating caregivers on coping skills ${ }^{14}$

Involving caregivers in individualized care plan and problem list development ${ }^{14-18,20-22}$
Not evaluated

Not evaluated

Not evaluated

No effect ${ }^{14,18}$

47.2\% Received as much help as needed with behavioral problems vs $29 \%$ in usual care $(P=.01)^{16}$

The rate of antidementia medication prescription by family physicians was increased from $42 \%$ to $86 \%$ and the rate of neuroleptic prescription decreased ${ }^{21,22}$

No effect ${ }^{14}$

No effect ${ }^{14,18}$

$27.3 \%$ of patients were enrolled in Safe Return vs $8.4 \%$ in usual care $(P=.001)^{16}$

In 2 studies, caregiver mood improved at 12 months $(P=.03)^{14,18}$; another found no effect at 18 months $(P=.33)^{14}$

Caregiver burden was not affected $(P=.49)^{17,18}$

Caregivers' support systems were adequate in $80.4 \%$ of cases vs $45 \%$ in usual care $(P=.001)^{16}$

$40.7 \%$ of caregivers received services vs $19.2 \%$ in usual care $(P=.002)^{16}$

Caregivers were socially supported $(P=.03)^{16}$

$38.7 \%$ of caregivers received in-home help vs $28.9 \%$ in usual care $(P=.02)^{16}$

$100 \%$ of caregivers were satisfied with home help ${ }^{17}$

Caregiver confidence and mastery were greater in CM $(P=.001)^{16}$

$38.2 \%$ of caregivers were involved in care plan development vs $22.1 \%$ in usual care $(P=.001)^{16}$

In $82.5 \%$ of cases, caregiver gave input on behavior issues vs $39 \%$ in usual care $(P=.001)^{16}$

$96 \%$ of caregivers were satisfied with discussion of patient's health problems ${ }^{17}$

$\mathrm{ADL}=$ activities of daily life; $\mathrm{CM}=$ case management; $\mathrm{IADL}=$ instrumental activities of daily living

a Only 1 of the studies on CM interventions enrolled patients not already diagnosed with dementia. ${ }^{21}$ 
Qualitative studies clearly described their inclusion and exclusion criteria, methods of analysis, and contexts. Exclusion of studies of lower quality did not change the overall results (Supplemental Appendix 5, available at http://annfammed.org/content/14/2/166/suppl/DC1).

\section{DISCUSSION}

This is the first systematic mixed-studies review conducted to evaluate whether CM meets the needs of patients with dementia and their caregivers. The main novelty of our review is that we first identified the needs from the perspectives of patients and their caregivers and only then evaluated whether CM targeted their needs and led to the desired outcomes. Our systematic review showed that CM addressed most needs of patients and caregivers. It also demonstrated that some very common needs (eg, early diagnosis) are still overlooked, while other needs (eg, education/information) are well targeted.

The most frequently reported need was early diagnosis of dementia. The impact of $\mathrm{CM}$ on this important need, however, has not been evaluated. While there is no consensus among health care profes-

Figure 1. Forest plot of standardized mean differences of case management vs control by subgroups.

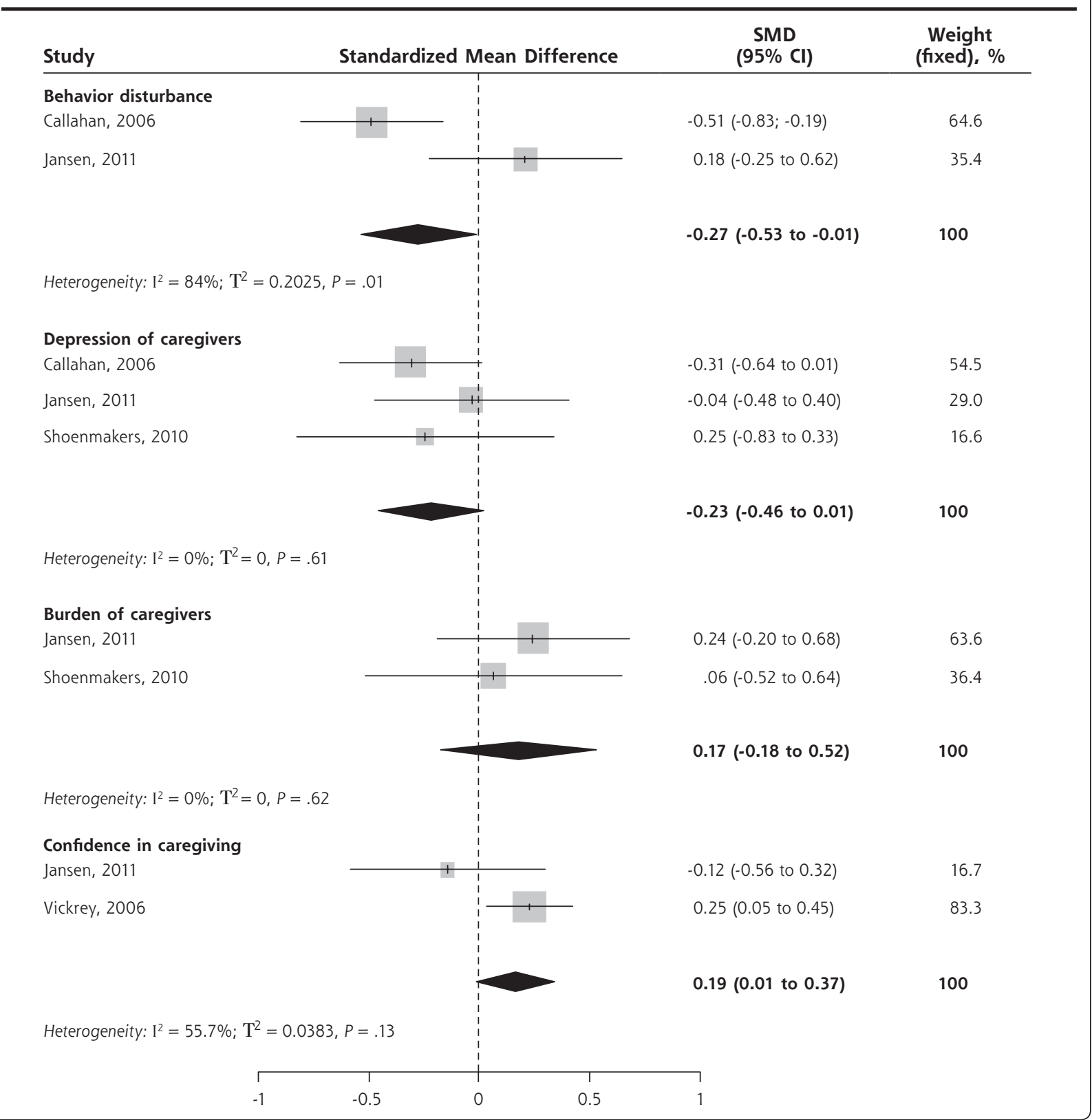


sionals on the early diagnosis of dementia, ${ }^{100-103}$ our systematic review suggests that patients and their caregivers would like to receive an early diagnosis. Early diagnosis of dementia does not necessarily change the disease's course, ${ }^{104}$ but it prompts health care professionals to identify the needs earlier and thus sustain the quality of life for both the patient and the caregiver. ${ }^{105}$ Moreover, it may positively affect appropriate medication prescription, decrease levels of caregiver burden and depression, and diminish the risk of early placement in a long-term care facility. ${ }^{106,107}$

The second most frequently reported need was education and counseling on the disease. This finding is in line with those of previous research, which has showed that most unmet needs were related to a lack of knowledge about the existing services, progression of dementia, and management of behavioral problems. ${ }^{29,79,108,109}$ Unlike early diagnosis, this need seems to be well targeted and appropriately addressed by CM.

Identification of the needs of patients and their caregivers is the basis for the development of interventions sensitive to these needs. ${ }^{6} \mathrm{CM}$ focuses on integration of medical and community services to deliver patient-centered care according to the specific needs of individual patients. ${ }^{13}$ The key element of $\mathrm{CM}$ is the collaboration of case managers with family physicians. Regular communication between case managers and family physicians is essential to the patient-centered care targeting these vulnerable populations; it allows family physicians to make timely modifications of their care plans.

Formal training of case managers in care of the elderly is a valuable asset to the care. ${ }^{14-18,20}$ Case managers specialized in dementia care can assess needs promptly and follow up regularly. For instance, they are better able to evaluate the needs of patients with regards to daily activities and orient them to the appropriate services (eg, mobility improvement programs). ${ }^{14-16}$ They also assess the needs for information and support and guide the patient-caregiver dyad to the appropriate services (eg, the Alzheimer Society or the Alzheimer's Association). ${ }^{15,16,20}$ Moreover, as the first point of contact for the dyad, they appear to be more easily reachable than family physicians. ${ }^{14-18,20-22}$ Our previous studies demonstrated that the effectiveness of CM depends on a small caseload, regular and proactive follow-up, and transparent communication among health care professionals. ${ }^{110,111}$

\section{Limitations}

As in any systematic review, we may have missed studies that we should have included. It is unlikely, however, that we missed large studies, as the literature search was comprehensive and included publications in
3 languages (English, French, and Russian). The metaanalysis of the effects of CM was conducted on a limited number of available studies, but it was exploratory; its conclusion should be considered with caution. The limited number of available studies on CM in which family physicians collaborate with case managers necessarily limited our review.

\section{Future Research}

Future studies are needed to evaluate the effects of $\mathrm{CM}$ on the needs that are overlooked-early diagnosis of dementia, legal issues, and financial issues. An avenue for some future studies could be the integration of social workers into primary care to assist with financial and legal issues of the dyad. ${ }^{16}$ Family physicians and researchers should perceive the needs of the dyad as unique features of patient-centered outcomes research related to primary care.

To read or post commentaries in response to this article, see it online at http://www.annfammed.org/content/14/2/166.

Key words: case management; dementia, primary care; collaborative care; patient-centered care; systematic review

Submitted June 6, 2015; submitted, revised, October 15, 2015; accepted November 8, 2015.

Previous presentation: The study was conducted by the first author as a scholarly project at the Family Medicine residency program of the McGill University; St. Mary's hospital, Montreal, Canada. The preliminary results have been presented at the North American Primary Care Research Group (NAPCRG) conference, New York, New York, November 22 - 25, 2014, and received the Patient Choice Award http://www.annfammed.org/content/13/3/286.full.

Acknowledgments: The authors would like to thank Alina Dyachenko, biostatistician, St Mary's Research Center, McGill University, for her assistance with statistical analysis; Muriel Gueriton, specialized librarian, Solidage, McGill University - Université de Montréal Research Group on Frailty and Aging, for her assistance with literature search; Quan Nha Hong, McGill University, for assistance with the methodological quality assessment; research assistant Martin Beauchamp for assistance with study selection; Daniëlle Jansen, Birgitte Schoenmakers, and Richard Fortinsky for sharing the data.

Supplementary materials: Available at http://www.AnnFamMed. org/content/14/2/166/suppl/DC1/.

\section{References}

1. Alzheimer's Association. Alzheimer's Disease Facts and Figures, 2014. Chicago, IL: Alzheimer's Association; 2014. Volume 10, Issue 2.

2. Alzheimer Society of Canada. http://www.alzheimer.ca. Accessed Sep 7, 2015.

3. Dudgeon S. Rising Tide: The Impact of Dementia on Canadian Society. Toronto, Canada: Alzheimer Society of Canada, 2010.

4. Prince M, Wimo A. World Alzheimer Report 2015. The Global Impact of Dementia. An Analysis of Prevalence, Incidence, Cost and Trends. London, England: Alzheimer's Disease International, 2015. 
5. Mathers C, Leonardi M. Global Burden of Dementia in the Year 2000: summary of methods and data sources. Geneva, Switzerland: World Health Organization, 2000.

6. van der Roest HG, Meiland FJ, Maroccini R, Comijs HC, Jonker C, Dröes RM. Subjective needs of people with dementia: a review of the literature. Int Psychogeriatr. 2007;19(3):559-592.

7. Dupuis S, Epp T, Smale B. Caregivers of Persons with Dementia: Roles, Experiences, Supports, and Coping. A Literature Review. Ontario, Canada: University of Waterloo, 2004

8. World Health Organization, Alzheimer's Disease International. Dementia: A Public Health Priority. Geneva, Switzerland: World Health Organization, 2012.

9. Bergman H. Report of the Committee of Experts for the Development of an Action Plan on Alzheimer's Disease and Related Disorders. Montreal, Canada: Alzheimer Society of Montreal, 2009.

10. Bamford C, Poole M, Brittain K, et al; CAREDEM team. Understanding the challenges to implementing case management for people with dementia in primary care in England: a qualitative study using Normalization Process Theory. BMC Health Serv Res. 2014;14:549.

11. Iliffe S, Robinson L, Bamford C, et al; CAREDEM research team. Introducing case management for people with dementia in primary care: a mixed-methods study. Br J Gen Pract. 2014;64(628): e735-e741

12. Morales-Asencio JM, Gonzalo-Jiménez E, Martin-Santos FJ, et al. Effectiveness of a nurse-led case management home care model in Primary Health Care. A quasi-experimental, controlled, multicentre study. BMC Health Serv Res. 2008;8:193.

13. Case Management Society of America. What is a case manager? http://www.cmsa.org/Home/CMSA/WhatisaCaseManager/ tabid/224/Default.aspx. Accessed Feb 12, 2016.

14. Callahan CM, Boustani MA, Unverzagt FW, et al. Effectiveness of collaborative care for older adults with Alzheimer disease in primary care: a randomized controlled trial. JAMA. 2006;295(18):2148-2157.

15. Fortinsky RH, Delaney C, Harel O, et al. Results and lessons learned from a nurse practitioner-guided dementia care intervention for primary care patients and their family caregivers. Res Gerontol Nurs. 2014;7(3):126-137.

16. Vickrey BG, Mittman BS, Connor KI, et al. The effect of a disease management intervention on quality and outcomes of dementia care: a randomized, controlled trial. Ann Intern Med. 2006;145(10): 713-726.

17. Jansen AP, van Hout HP, Nijpels $G$, et al. Effectiveness of case management among older adults with early symptoms of dementia and their primary informal caregivers: a randomized clinical trial. Int J Nurs Stud. 2011;48(8):933-943.

18. Schoenmakers B, Buntinx F, Delepeleire J. Supporting family carers of community-dwelling elder with cognitive decline: a randomized controlled trial. Int J Family Med. 2010;2010:184152.

19. Laurant MG, Hermens RP, Braspenning JC, Sibbald B, Grol RP. Impact of nurse practitioners on workload of general practitioners: randomised controlled trial. BMJ. 2004;328(7445):927.

20. Stevenson G, Herschell JDK. An enhanced assessment and support team (EAST) for dementing elders - review of a Scottish regional initiative. J Ment Health. 2006;15(2):251-258.

21. Jedenius E, Johnell K, Fastbom J, Strömqvist J, Winblad B, Andreasen N. Dementia management programme in a community setting and the use of psychotropic drugs in the elderly population. Scand J Prim Health Care. 2011;29(3):181-186.

22. Jedenius E, Wimo A, Strömqvist J, Andreasen N. A Swedish programme for dementia diagnostics in primary healthcare. Scand J Prim Health Care. 2008;26(4):235-240.

23. Reilly S, Miranda-Castillo C, Malouf R, et al. Case management approaches to home support for people with dementia. Cochrane Database Syst Rev. 2015;1:CD008345.
24. Koch T, lliffe S. Dementia diagnosis and management: a narrative review of changing practice. Br J Gen Pract. 2011;61(589):e513-e525.

25. Koch T, Iliffe S, Manthorpe J, et al; CARE-DEM. The potential of case management for people with dementia: a commentary. Int J Geriatr Psychiatry. 2012;27(12):1305-1314.

26. Pimouguet C, Lavaud T, Dartigues JF, Helmer C. Dementia case management effectiveness on health care costs and resource utilization: a systematic review of randomized controlled trials. J Nutr Health Aging. 2010;14(8):669-676.

27. Somme D, Trouve H, Dramé M, Gagnon D, Couturier $Y$, Saint-Jean $O$. Analysis of case management programs for patients with dementia: a systematic review. Alzheimers Dement. 2012;8(5):426-436.

28. Tam-Tham H, Cepoiu-Martin M, Ronksley PE, Maxwell CJ, Hemmelgarn BR. Dementia case management and risk of long-term care placement: a systematic review and meta-analysis. Int J Geriatr Psychiatry. 2013;28(9):889-902.

29. Peeters JM, Van Beek AP, Meerveld JH, Spreeuwenberg PM, Francke AL. Informal caregivers of persons with dementia, their use of and needs for specific professional support: a survey of the National Dementia Programme. BMC Nurs. 2010;9:9.

30. Raivio M, Eloniemi-Sulkava U, Laakkonen $\mathrm{ML}$, et al. How do officially organized services meet the needs of elderly caregivers and their spouses with Alzheimer's disease? Am J Alzheimers Dis Other Demen. 2007;22(5):360-368.

31. Association of American Medical Colleges. The Medical Home: AAMC Position Statement. Washington, DC: Association of American Medical Colleges, 2008.

32. The College of Family Physicians of Canada. Patient-Centered Primary Care in Canada: Bring it on Home. Ontario, Canada: The College of Family Physicians of Canada, 2009.

33. Gaugler JE, Kane RL, Kane RA, Newcomer R. Unmet care needs and key outcomes in dementia. J Am Geriatr Soc. 2005;53(12): 2098-2105.

34. Aggarwal N, Vass AA, Minardi HA, Ward R, Garfield C, Cybyk B. People with dementia and their relatives: personal experiences of Alzheimer's and of the provision of care. J Psychiatr Ment Health Nurs. 2003;10(2):187-197.

35. Vernooij-Dassen M, Lamers C, Bor J, Felling A, Grol R. Prognostic factors of effectiveness of a support program for caregivers of dementia patients. Int J Aging Hum Dev. 2000;51(4):259-274.

36. Fixsen D, Blase K, Friedman R, Wallace F. Implementation Research: A Synthesis of the Literature. Tampa, FL: University of South Florida, Louis de la Parte Florida Mental Health Institute, 2005.

37. Popay J. Moving Beyond Effectiveness in Evidence Synthesis: Methodological Issues in the Synthesis of Diverse Sources of Evidence. London, England: National Institute for Health and Clinical Excellence, 2006.

38. Kopke S, McCleery J. Systematic reviews of case management: Too complex to manage? Cochrane Database Syst Rev. 2015;1: Ed000096.

39. Harden A. Mixed-Methods Systematic Reviews: Integrating Quantitative and Qualitative Findings. Austin, TX: National Center for the Dissemination of Disability Research (NCDDR), 2010.

40. Pluye P, Hong QN. Combining the Power of Stories and the Power of Numbers: Mixed Methods Research and Mixed Studies Reviews. Annu Rev Public Health. 2014;35:29-45.

41. Weiss ME. Case management as a tool for clinical integration. Adv Pract Nurs Q. 1998;4(1):9-15.

42. Canadian Institutes of Health Research. http://www.cihr-irsc.gc.ca. Accessed Sep 7, 2015.

43. Moher D, Liberati A, Tetzlaff J, Altman DG; PRISMA Group. Preferred reporting items for systematic reviews and meta-analyses: the PRISMA statement. Int J Surg. 2010;8(5):336-341. 
44. Pluye P, Gagnon MP, Griffiths F, Johnson-Lafleur J. A scoring system for appraising mixed methods research, and concomitantly appraising qualitative, quantitative and mixed methods primary studies in Mixed Studies Reviews. Int J Nurs Stud. 2009;46(4):529-546.

45. Pace $R$, Pluye $P$, Bartlett $G$, et al. Testing the reliability and efficiency of the pilot Mixed Methods Appraisal Tool (MMAT) for systematic mixed studies review. Int J Nurs Stud. 2012;49(1):47-53.

46. Souto RQ, Khanassov V, Hong QN, Bush PL, Vedel I, Pluye P. Systematic mixed studies reviews: updating results on the reliability and efficiency of the Mixed Methods Appraisal Tool. Int J Nurs Stud. 2015;52(1):500-501.

47. Mays N, Pope C, Popay J. Systematically reviewing qualitative and quantitative evidence to inform management and policy-making in the health field. J Health Serv Res Policy. 2005;10 Suppl 1:6-20.

48. Snilstveit B, Oliver S, Vojtkova M. Narrative approaches to systematic review and synthesis of evidence for international development policy and practice. J Dev Effect. 2012;4(3):409-29.

49. The R project for statistical computing. http://www.r-project.org/. Accessed Feb 23, 2016.

50. Egger M, Smith G, Altman D. Systematic Reviews in Health Care: Meta-Analysis in Context. 2nd ed. London: BMJ Publishing Group; 2008.

51. Cohen J. A power primer. Psychol Bull. 1992;112(1):155-9.

52. Górska S, Forsyth K, Irvine L, et al. Service-related needs of older people with dementia: perspectives of service users and their unpaid carers. Int Psychogeriatr. 2013;25(7):1107-1114.

53. Flynn R, Mulcahy H. Early-onset dementia: the impact on family care-givers. Br J Community Nurs. 2013;18(12):598-606.

54. Bakker C, de Vugt ME, Vernooij-Dassen M, van Vliet D, Verhey FR, Koopmans RT. Needs in early onset dementia: A qualitative case from the NeedYD study. Am J Alzheimers Dis Other Demen. 2010; 25(8):634-640.

55. Mushi D, Rongai A, Paddick SM, Dotchin C, Mtuya C, Walker R. Social representation and practices related to dementia in Hai District of Tanzania. BMC Public Health. 2014;14:260.

56. Nichols KR, Fam D, Cook C, et al. When dementia is in the house: needs assessment survey for young caregivers. Can J Neurol Sci. 2013:40(1):21-28.

57. Qadir F, Gulzar W, Haqqani S, Khalid A. A pilot study examining the awareness, attitude, and burden of informal caregivers of patients with dementia. Care Manag J. 2013;14(4):230-240.

58. Tasc S, Tekinsoy Kartn P, Ceyhan O, Sungur G, Göris S. Living with an Alzheimer patient in Turkey. J Neurosci Nurs. 2012;44(4):228-234.

59. Vaingankar JA, Subramaniam M, Picco L, et al. Perceived unmet needs of informal caregivers of people with dementia in Singapore. Int Psychogeriatr. 2013;25(10):1605-1619.

60. Bowes A, Wilkinson H. 'We didn't know it would get that bad': South Asian experiences of dementia and the service response. Health Soc Care Community. 2003;11(5):387-396.

61. Zhan L. Caring for family members with Alzheimer's disease: perspectives from Chinese American caregivers. J Gerontol Nurs. 2004; 30(8):19-29.

62. Kuhn D. Caring for relatives with early stage Alzheimer's disease: An exploratory study. Am J Alzheimers Dis Other Demen. 1998;13(4): 189-196.

63. Shaji KS, Smitha K, Lal KP, Prince MJ. Caregivers of people with Alzheimer's disease: a qualitative study from the Indian 10/66 Dementia Research Network. Int J Geriatr Psychiatry. 2003;18(1):1-6.

64. Samsi K, Abley C, Campbell S, et al. Negotiating a labyrinth: experiences of assessment and diagnostic journey in cognitive impairment and dementia. Int J Geriatr Psychiatry. 2014;29(1):58-67.

65. Singh P, Hussain R, Khan A, Irwin L, Foskey R. Dementia care: intersecting informal family care and formal care systems. J Aging Res. 2014;2014:486521.
66. Smith A. Caregiver Needs. Clin Gerontol. 2001;24(1-2):3-26.

67. Smith K, Flicker L, Shadforth G, et al. 'Gotta be sit down and worked out together': views of Aboriginal caregivers and service providers on ways to improve dementia care for Aboriginal Australians. Rural Remote Health. 2011;11(2):1650.

68. Chan WC, Ng C, Mok CC, Wong FL, Pang SL, Chiu HF. Lived experience of caregivers of persons with dementia in Hong Kong: a qualitative study. East Asian Arch Psychiatry. 2010;20(4):163-168.

69. Innes A, Blackstock K, Mason A, Smith A, Cox S. Dementia care provision in rural Scotland: service users' and carers' experiences. Health Soc Care Community. 2005;13(4):354-365.

70. Holst G, Hallberg IR. Exploring the meaning of everyday life, for those suffering from dementia. Am J Alzheimers Dis Other Demen. 2003;18(6):359-365.

71. Gilmour JA, Huntington AD. Finding the balance: living with memory loss. Int J Nurs Pract. 2005;11(3):118-124.

72. Marzanski M. Would you like to know what is wrong with you? On telling the truth to patients with dementia. J Med Ethics. 2000;26(2):108-113.

73. Wuest J, Ericson PK, Stern PN, Irwin GW Jr. Connected and disconnected support: the impact on the caregiving process in Alzheimer's disease. Health Care Women Int. 2001;22(1-2):115-130.

74. Johnston D, Samus QM, Morrison A, et al. Identification of community-residing individuals with dementia and their unmet needs for care. Int J Geriatr Psychiatry. 2011;26(3):292-298.

75. Commissaris CJ, Jolles J, Verhey FR Jr, Kok GJ. Problems of caregiving spouses of patients with dementia. Patient Educ Couns. 1995;25 (2):143-149.

76. Li H, Kyrouac GA, McManus DQ, Cranston RE, Hughes S. Unmet home care service needs of rural older adults with Alzheimer's disease: a perspective of informal caregivers. J Gerontol Soc Work. 2012;55(5):409-425.

77. Miranda-Castillo C, Woods B, Galboda K, Oomman S, Olojugba C, Orrell M. Unmet needs, quality of life and support networks of people with dementia living at home. Health Qual Life Outcomes. 2010;8:132.

78. Miranda-Castillo C, Woods B, Orrell M. People with dementia living alone: what are their needs and what kind of support are they receiving? Int Psychogeriatr. 2010;22(4):607-617.

79. van der Roest HG, Meiland FJ, Comijs HC, et al. What do community-dwelling people with dementia need? A survey of those who are known to care and welfare services. Int Psychogeriatr. 2009;21(5):949-965.

80. Rosa E, Lussignoli $G$, Sabbatini $F$, et al. Needs of caregivers of the patients with dementia. Arch Gerontol Geriatr. 2010;51(1):54-58.

81. Leggett AN, Zarit S, Taylor A, Galvin JE. Stress and burden among caregivers of patients with Lewy body dementia. Gerontologist. 2011;51(1):76-85.

82. Hirakawa Y, Kuzuya M, Enoki H, Uemura K. Information needs and sources of family caregivers of home elderly patients. Arch Gerontol Geriatr. 2011;52(2):202-205.

83. Philp I, McKee KJ, Meldrum P, et al. Community care for demented and non-demented elderly people: a comparison study of financial burden, service use, and unmet needs in family supporters. BMJ. 1995;310(6993):1503-1506.

84. Meaney AM, Croke M, Kirby M. Needs assessment in dementia. Int J Geriatr Psychiatry. 2005;20(4):322-329.

85. Black BS, Johnston D, Rabins PV, Morrison A, Lyketsos C, Samus QM. Unmet needs of community-residing persons with dementia and their informal caregivers: findings from the maximizing independence at home study. J Am Geriatr Soc. 2013;61(12):2087-2095.

86. Wolfs CA, de Vugt ME, Verkaaik M, Verkade PJ, Verhey FR. Empowered or overpowered? Service use, needs, wants and demands in elderly patients with cognitive impairments. Int J Geriatr Psychiatry. 2010;25(10):1006-1012. 
87. Nurock S, Wojciechowska M. What real outcomes matter to caregivers? Int Psychogeriatr. 2007;19(3):355-362.

88. Armari E, Jarmolowicz A, Panegyres PK. The needs of patients with early onset dementia. Am J Alzheimers Dis Other Demen. 2013; 28(1):42-46.

89. Chow TW, Pio FJ, Rockwood K. An international needs assessment of caregivers for frontotemporal dementia. Can J Neurol Sci. 2011;38(5):753-757.

90. Chung JC. Care needs assessment of older Chinese individuals with dementia of Hong Kong. Aging Ment Health. 2006;10(6):631-637.

91. Li H. Unmet service needs: a comparison between dementia and non-dementia caregivers. Home Health Care Serv Q. 2012;31(1):41-59.

92. Rosness TA, Haugen PK, Gausdal M, Gjøra L, Engedal K. Carers of patients with early-onset dementia, their burden and needs: a pilot study using a new questionnaire-care-EOD. Int J Geriatr Psychiatry. 2012;27(10):1095-1096.

93. Wackerbarth SB, Johnson MM. Essential information and support needs of family caregivers. Patient Educ Couns. 2002;47(2):95-100.

94. Georges J, Jansen S, Jackson J, Meyrieux A, Sadowska A, Selmes M. Alzheimer's disease in real life-the dementia carer's survey. Int J Geriatr Psychiatry. 2008;23(5):546-551.

95. Hinton L, Chambers D, Velasquez A, Gonzalez H, Haan M. Dementia Neuropsychiatric Symptom Severity, Help-Seeking Patterns, and Family Caregiver Unmet Needs in the Sacramento Area Latino Study on Aging (SALSA). Clin Gerontol. 2006;29(4):1-15.

96. Lai C, Chung JC. Caregivers' informational needs on dementia and dementia care. Asian J Gerontol Geriatr. 2007;2:78-87.

97. Judge KS, Bass DM, Snow AL, et al. Partners in dementia care: a care coordination intervention for individuals with dementia and their family caregivers. Gerontologist. 2011;51(2):261-272.

98. Stirling C, Andrews S, Croft T, Vickers J, Turner P, Robinson A. Measuring dementia carers' unmet need for services-an exploratory mixed method study. BMC Health Serv Res. 2010;10:122.

99. Bowes A, Wilkinson H. 'We didn't know it would get that bad': South Asian experiences of dementia and the service response. Health Soc Care Community. 2003;11(5):387-96.
100. Dhedhi SA, Swinglehurst D, Russell J. 'Timely' diagnosis of dementia: what does it mean? A narrative analysis of GPs' accounts. BM] Open. 2014;4(3):e004439.

101. Fan T, Rossi C. Screening for Cognitive Impairment in Older Adults. Am Fam Physician. 2015;92(2):125-126.

102. Moyer VA; U.S. Preventive Services Task Force. Screening for cognitive impairment in older adults: U.S. Preventive Services Task Force recommendation statement. Ann Intern Med. 2014;160(11):791-797.

103. Moore A, Patterson C, Lee L, Vedel I, Bergman H; Canadian Consensus Conference on the Diagnosis and Treatment of Dementia. Fourth Canadian Consensus Conference on the Diagnosis and Treatment of Dementia: recommendations for family physicians. Can Fam Physician. 2014;60(5):433-438.

104. Larson EB, Shadlen MF, Wang L, et al. Survival after initial diagnosis of Alzheimer disease. Ann Intern Med. 2004;140(7):501-509.

105. Covinsky KE, Yaffe K. Dementia, prognosis, and the needs of patients and caregivers. Ann Intern Med. 2004;140(7):573-574.

106. Health Council of Canada. Seniors in Need, Caregivers in Distress: What Are the Home Care Priorities for Seniors in Canada? Ontario, Canada: Health Council of Canada, 2012.

107. Bossen AL, Specht JK, McKenzie SE. Needs of people with earlystage Alzheimer's disease: reviewing the evidence. J Gerontol Nurs. 2009;35(3):8-15.

108. Brodaty H, Green A, Koschera A. Meta-analysis of psychosocial interventions for caregivers of people with dementia. J Am Geriatr Soc. 2003;51(5):657-664.

109. Brodaty H, Thomson C, Thompson C, Fine M. Why caregivers of people with dementia and memory loss don't use services. Int J Geriatr Psychiatry. 2005;20(6):537-546.

110. Khanassov V, Vedel I, Pluye P. Barriers to implementation of case management for patients with dementia: a systematic mixed studies review. Ann Fam Med. 2014;12(5):456-465.

111. Khanassov V, Vedel I, Pluye P. Case management for dementia in primary health care: a systematic mixed studies review based on the diffusion of innovation model. Clin Interv Aging. 2014;9:915-928. 